E3S Web of Conferences 1, 16009 (2013)

DOI: $10.1051 / \mathrm{e} 3$ sconf/20130116009

(c) Owned by the authors, published by EDP Sciences, 2013

\title{
Root proteome response to growth on tannery waste in three different poplar species with various adaptation abilities
}

\author{
A. Zemleduch-Barylska ${ }^{1}$ and G. Lorenc-Plucińska ${ }^{2}$ \\ ${ }^{1}$ Institute of Dendrology, Polish Academy of Sciences, Parkowa 5, 62-035 Kórnik, POLAND, agata.zemleduch@wp.pl \\ ${ }^{2}$ Institute of Dendrology, Polish Academy of Sciences, Parkowa 5, 62-035 Kórnik, POLAND, glp@man.poznan.pl
}

\begin{abstract}
In our study we compared growth of three poplar clones (Populus tremula $\times$ alba, P. alba 'Villafranca" and P. nigra) on chromium-containing solid tannery waste. Tolerance index of saplings ranged from only $25 \%$ for $P$. nigra up to $80 \%$ for $P$. tremula $x$ alba. Standard morphological, chemical and biochemical analyses also confirmed significant differences in reaction of all tested clones to such growth conditions. Preliminary proteomic study showed an unequal level of changes in protein profiles from roots in different poplars.
\end{abstract}

Key words: tannery waste, Populus spp., biomass, root proteome, trace metals uptake, phytoremediation

\section{Introduction}

Chromium contamination of soil and water as a result of tannery industry activities is of a great concern in many developing countries. It was estimated that in 2006 Poland had over $5 \mathrm{mln}$ tones of chromium-containing solid waste, of which $0,5 \mathrm{mln}$ tones came from tanneries. So far landfilling is the most common way of disposal for both by-products from leather processing and $\mathrm{Cr}$-rich sediments from wastewater treatment. However it may cause serious consequences for ecosystem. Reclamation of such areas with physical or chemical methods turned out to be complex and expensive. Biotechnologies, for example phytoremediation could become an environmental-friendly and cost-effective alternative. Afforestation of tannery waste dumping sites can take advantages of tolerance of selected tree species to toxic chromium levels in ground and their ability to use nutrients abundance that waste contains. Poplar trees (from Salicaceae family) have all these predispositions for phytoremediation purposes and also are considered as bioenergy crops, what creates additional possibilities. They grow fast, yield high biomass, can be easily propagated in vegetative way and are proved to be very tolerant to various abiotic stress factors (Marmiroli 2011). However poplar species, clones or cultivars could differ in their viability, $\mathrm{Cr}$ accumulation in tissues, uptake and translocation of other elements as well as susceptibility to oxidative stress and abilities to deal with it. All these traits are among factors that influence the way that tree adapt its metabolism to certain environmental conditions and their evaluation could help in selection of best candidate for tannery waste phytoremediation.

\section{Material and Methods}

Root suckers of hybrid poplar (Populus tremula $\times P$. $a l b a)$ and rooted shoot cuttings of white ( $P$. alba 'Villafranca') and black poplar ( $P$. nigra) were grown on solid waste from an inactive (for several years) landfill site of the closed tannery in Kępice or on control, unpolluted soil from ID PAS experimental forest. Tested sediment was characterized by significantly different total and bioavailable concentrations of elements; higher $\mathrm{Cr}$ and $\mathrm{Fe}$ (probably due to iron alum and also plant tanning agents use in tanning process), $\mathrm{Cd}, \mathrm{Cu}$ as well as nutrients $\mathrm{N}, \mathrm{S}, \mathrm{P}$, whereas lower $\mathrm{Mg}, \mathrm{K}, \mathrm{Mn}$ compared to control soil. The trial was carried out in a greenhouse, plants grew in ca. 2-litre pots containing waste or soil for 18-22 weeks. After the end of the experiment, some morphological and chemical analyses for each treatment and plant organ (stem, leaves, roots) were done according to standard methods. We performed also biochemical test for membrane lipid peroxidation (malondialdehyde formation). Finely, we carried out protein extraction, from frozen tissue, and 2-dimensional electrophoresis to 


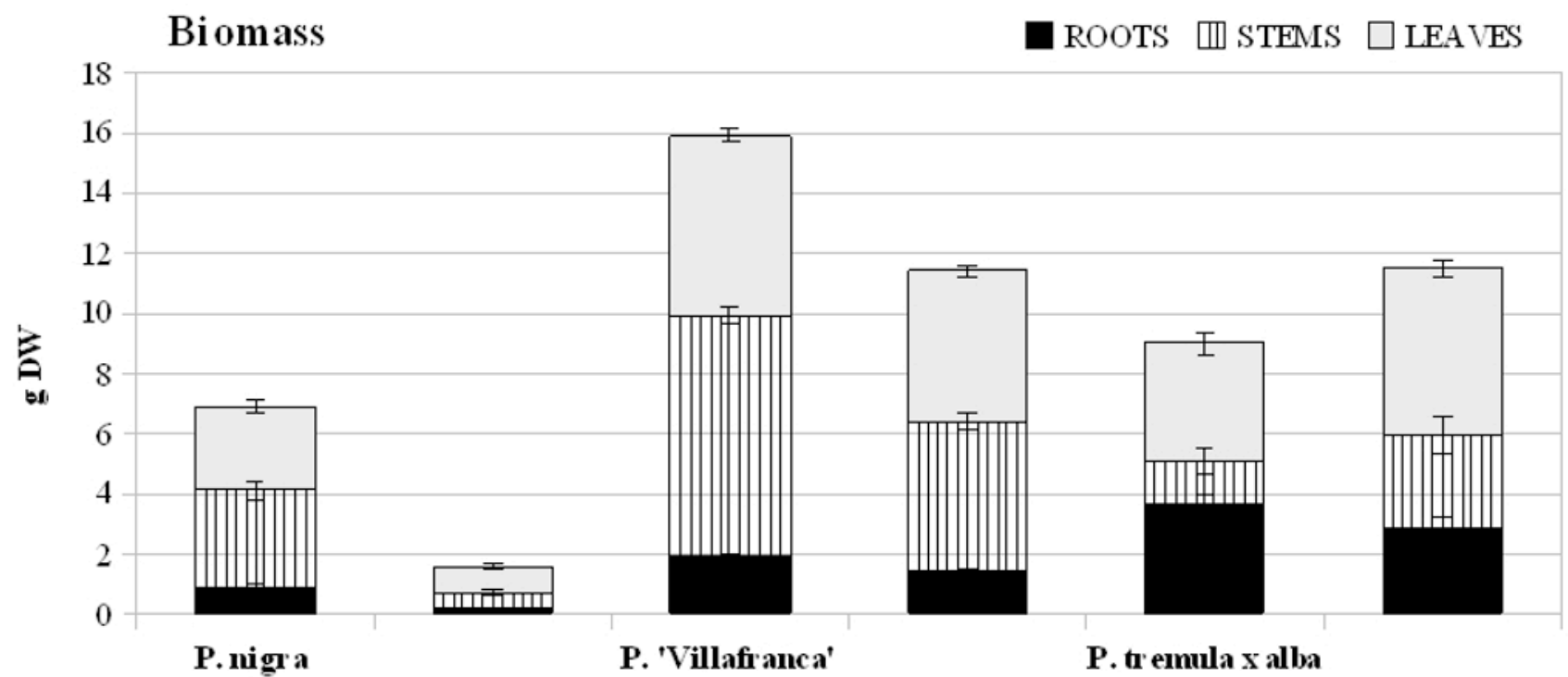

Fig. 1. Leaves, stems, roots and total biomass of poplar saplings after 18 ( $P$. 'Villafranca' and $P$. nigra) and $22(P$. tremula) weeks of growth on the control soil and on tannery waste. Means $\pm \mathrm{SE}$

A)

$\square$ P. tremula $x$ alba $\square$ P. 'Villafranca'

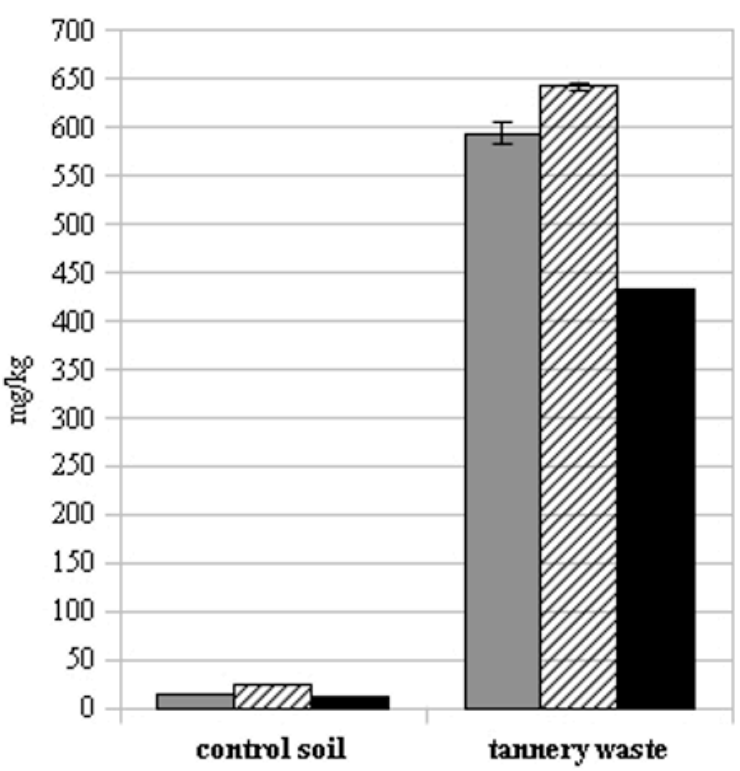

$\mathrm{Cr}$

B)

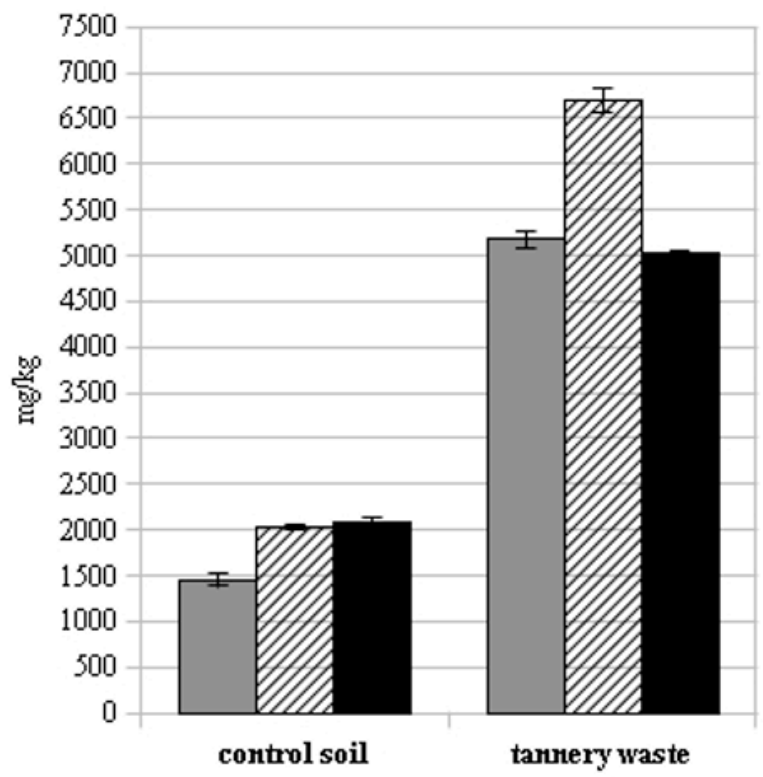

Fig. 2. Concentration of chromium (A) and iron (B) in poplar saplings grown on control soil and on tannery waste. Mean $\pm \mathrm{SE}$.

evaluate changes in root protein profiles of poplar saplings grown on tannery waste.

\section{Results and Discussion}

In our experiment we found that tannery waste did not severely impair growth in all of tested poplars. Only for Populus nigra we observed a definite decline in biomass, while hybrid poplar $(P$. tremula $\times$ alba) grew on tannery waste even better than on control soil (Fig. 1). It was also shown by the lowest tolerant index of Populus nigra (25\%) compared to $P$. 'Villafranca' (72\%) and $P$. tremula $\times$ alba $(80 \%)$. Chromium concentration in all saplings exceed critic level of $100 \mathrm{mg} / \mathrm{kg}$ and in all cases about $97 \%$ of it was accumulated in the roots (Fig. 2 A). Also iron concentration was 2.4 (black poplar) to 4 times (hybrid poplar) higher than in plants grown on control soil (Fig. 2B). Content of other elements, like P, N, S, K, $\mathrm{Ca}, \mathrm{Na}$ was altered as well. $P$. nigra took up least amount of $\mathrm{Cr}$ and $\mathrm{Fe}$, however we observed greatly affected root 
Table 1. Comparison of protein profiles (with ImageMaster Platinum 6.0 software) from the roots in control and treated poplar species. The spots common to both gels are termed matches.

\begin{tabular}{|c|c|c|c|c|c|c|}
\hline & \multicolumn{2}{|c|}{ P. tremula ${ }^{x}$ alba } & \multicolumn{2}{|c|}{ P. 'Villafranca' } & \multicolumn{2}{|c|}{ P. nigru } \\
\hline & control soil & tannery waste & control soil & tannery waste & \begin{tabular}{|c|} 
control soil \\
\end{tabular} & tannery waste \\
\hline Mean no. of spots $(n=3$ or 4$)$ & $1406 \pm 88$ & $1283 \pm 67$ & $1032 \pm 78$ & $1029 \pm 41$ & $1280 \pm 130$ & $1151 \pm 75$ \\
\hline No. of matches ( $n=3$ or 4 ) & $1367 \pm 97$ & $1216 \pm 86$ & $1077 \pm 145$ & $1156 \pm 88$ & $1266 \pm 133$ & $1066 \pm 98$ \\
\hline Mean $\%$ of matches & $89 \pm 4$ & $88 \pm 4$ & $86 \pm 8$ & $92 \pm 4$ & $86 \pm 5$ & $85 \pm 5$ \\
\hline No. of matches & \multicolumn{2}{|c|}{$1480 \pm 169$} & \multicolumn{2}{|c|}{$1256 \pm 81$} & \multicolumn{2}{|c|}{$1449 \pm 197$} \\
\hline$\%$ of matches & \multicolumn{2}{|c|}{$92 \pm 8$} & \multicolumn{2}{|c|}{$94 \pm 6$} & \multicolumn{2}{|c|}{$92 \pm 8$} \\
\hline No. of matches ${ }^{\star}$ & \multicolumn{2}{|c|}{112} & \multicolumn{2}{|c|}{94} & \multicolumn{2}{|c|}{44} \\
\hline$\%$ of matches ${ }^{*}$ & \multicolumn{2}{|c|}{7.6} & \multicolumn{2}{|r|}{7.5} & \multicolumn{2}{|r|}{3.0} \\
\hline No. of up-regulated matches ${ }^{*}$ & 79 & 33 & 55 & 39 & 26 & 18 \\
\hline$\%$ of up-regulated matches ${ }^{\star}$ & 70.5 & 29.5 & 58.5 & 41.5 & 59.1 & 40.9 \\
\hline
\end{tabular}

$\%$ of matches ( $=2 *$ matches / total spots in 2 gels)

* statistically significant difference $p \leq 0.05$, fold change $\geq 2$

morphology and biomass. We also found increase in lipid peroxidation in $P$. nigra roots, what was not characteristic for other poplars grown in the same conditions. This results indicated that black poplar antioxidative system may not work efficiently enough or is more susceptible to stress caused by tannery waste as a growth substrate. In order to evaluate changes in metabolism of poplars with various resistance to such growth conditions we made a comparison between root protein profiles obtained from control and treated plants. We found similar level of significant (at least 2-fold) changes (in about $7.5 \%$ of analysed protein pool) for $P$. tremula $\times$ alba and $P$. 'Villafranca' but it seems that they are not related to the same set of proteins. Surprisingly, P. nigra that showed the most of stress symptoms growing on tannery waste, had its proteome changed in only $3 \%$ (Table 1 ).

The explanation of such result could be more simple after identification of these proteins. Black poplar is generally not considered as a good candidate for phytoremediation purposes, because of lower tolerance to adverse environmental conditions compared to other species from Salicaceae family (Zacchini 2011). Lack of substantial changes in metabolism that could be seen in protein profile shift after growth on tannery waste may confirm little adaptation abilities of P. nigra.

\section{Conclusions}

Hybrid poplar as well as white poplar showed no obvious symptoms of tannery waste toxicity. Actually the second one grew even better than on control soil, probably because of greater ability to use nutrients from the waste. Almost all morphometrical and biochemical results obtained for black poplar contrasted with those of aforementioned clones. Identification of selected proteins characterized with quantitative changes in roots of all tested poplars after growth on tannery waste would help to understand their different reaction.

\section{Acknowledgements}

This work was supported by grant No. N N3050365 40 from the National Science Centre (NCN), Poland

\section{References}

Marmiroli M, Pietrini F, Maestri E, Zacchini M, Marmiroli $\mathrm{N}$ and Massacci A. Growth, physiological and molecular traits in Salicaceae trees investigated for phytoremediation of heavy metals and organics. Tree Physiol 2011; 31: 13191334.

Zacchini M, Iori V, Scarascia Mugnozza G, Pietrini F and Massacci A. Cadmium accumulation and tolerance in Populus nigra and Salix alba. Biologia Plantarum 2011; 55, 2, 383-386. 